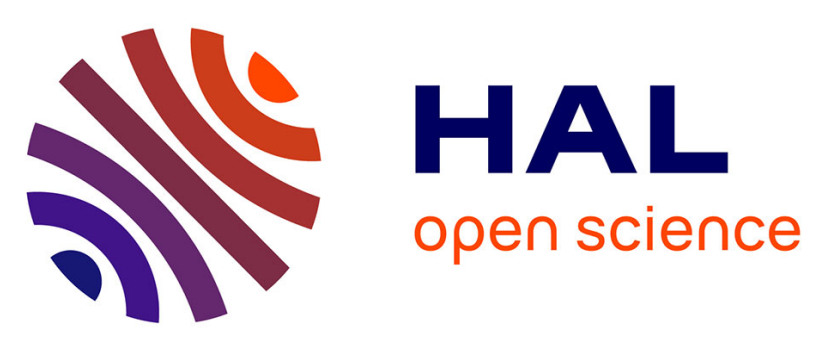

\title{
Seasonal variations of the composition of microbial biofilms in sandy tidal flats: Focus of fatty acids, pigments and exopolymers
}

Claire Passarelli, Tarik Meziane, Najet Thiney, Dominique Boeuf, Bruno Jesus, Mickael Ruivo, Christian Jeanthon, Cédric Hubas

\section{To cite this version:}

Claire Passarelli, Tarik Meziane, Najet Thiney, Dominique Boeuf, Bruno Jesus, et al.. Seasonal variations of the composition of microbial biofilms in sandy tidal flats: Focus of fatty acids, pigments and exopolymers. Estuarine, Coastal and Shelf Science, 2015, 153, pp.29-37. 10.1016/j.ecss.2014.11.013 . hal-01097244

\section{HAL Id: hal-01097244 \\ https://hal.sorbonne-universite.fr/hal-01097244}

Submitted on 19 Dec 2014

HAL is a multi-disciplinary open access archive for the deposit and dissemination of scientific research documents, whether they are published or not. The documents may come from teaching and research institutions in France or abroad, or from public or private research centers.
L'archive ouverte pluridisciplinaire HAL, est destinée au dépôt et à la diffusion de documents scientifiques de niveau recherche, publiés ou non, émanant des établissements d'enseignement et de recherche français ou étrangers, des laboratoires publics ou privés. 


\title{
Seasonal variations of the composition of microbial biofilms in sandy tidal flats: focus of fatty acids, pigments and exopolymers
}

\author{
Claire Passarelli*, ${ }^{,}$, Tarik Meziane ${ }^{1}$, Najet Thiney ${ }^{1}$, Dominique Boeuf ${ }^{2,3}$, Bruno Jesus ${ }^{4,5}$, \\ Mickael Ruivo $^{5}$, Christian Jeanthon ${ }^{2,3}$, Cédric Hubas ${ }^{1}$ \\ ${ }^{1}$ UMR BOREA 7208 CNRS/MNHN/UPMC/IRD, Muséum National d'Histoire Naturelle, \\ Bâtiment des Arthropodes, CP53, 61 rue Buffon, 75231 Paris Cedex 5, France \\ ${ }^{2}$ UPMC, Univ Paris VI, UMR 7144, Adaptation et Diversité en Milieu Marin, Station \\ Biologique, 29680 Roscoff, France \\ ${ }^{3}$ CNRS, UMR 7144, Adaptation et Diversité en Milieu Marin, Station Biologique, 29680 \\ Roscoff, France \\ ${ }^{4}$ LUNAM université, Université de Nantes, Mer Molécules Santé EA 2160, Faculté des \\ Sciences et Techniques, B.P. 92208, 44322 Nantes cedex 3, France \\ ${ }^{5}$ Centro de Biodiversidade, Genómica Integrativa e Funcional (BioFIG), Faculdade de \\ Ciências, Universidade de Lisboa, 1749-016 Lisboa, Portugal
}

Keywords: biofilms, biogenic structures, EPS, monosaccharide composition, fatty acids, pigments.

* corresponding author: claire.passarelli@mnhn.fr

Phone: 0033140793591 


\section{Abstract}

Biofilms, or microbial mats, are common associations of microorganisms in tidal flats; they generally consist of a large diversity of organisms embedded in a matrix of Extracellular Polymeric Substances (EPS). These molecules are mainly composed of carbohydrates and proteins, but their detailed monomer compositions and seasonal variations are currently unknown. Yet this composition determines the numerous roles of biofilms in these systems. This study investigated the changes in composition of carbohydrates in intertidal microbial mats over a year to decipher seasonal variations in biofilms and in varying hydrodynamic conditions. This work also aimed to assess how these compositions are related to microbial assemblages. In this context, natural biofilms whose development was influenced or not by artificial structures mimicking polychaete tubes were sampled monthly for over a year in intertidal flats of the Chausey archipelago. Biofilms were compared through the analysis of their fatty acid and pigment contents, and the monosaccharide composition of their EPS carbohydrates. Carbohydrates from both colloidal and bound EPS contained mainly glucose and, to a lower extent, galactose and mannose but they showed significant differences in their detailed monosaccharide compositions. These two fractions displayed different seasonal evolution, even if glucose accumulated in both fractions in summer; bound EPS only were affected by artificial biogenic structures. Sediment composition in fatty acids and pigments showed that microbial communities were dominated by diatoms and heterotrophic bacteria. Their relative proportions, as well as those of other groups like cryptophytes, changed between times and treatments. The changes in EPS composition were not fully explained by modifications of microbial assemblages but also depended on the processes taking place in sediments and on environmental conditions. These variations of EPS compositions are likely to alter different ecosystem processes such as biostabilisation or pollutants trapping. 


\section{Introduction}

In coastal soft-bottom areas, a large diversity of microbial mats exists; their composition depends on environmental conditions such as salinity, tidal height and duration of exposure, light, grain size, and organic matter input (Brotas et al., 1995; Franks and Stolz, 2009; Paterson and Hagerthey, 2001). Additionally, they are sensitive to anthropic actions such as eutrophication or antibiotic release in the environment (Lubarsky et al., 2012; Sawall et al., 2012). These biofilms are often very productive and they also provide different ecosystem services, such as nutrient recycling, degradation of pollutants and sediment stabilisation, and they are essential for the recruitment of numerous benthic organisms (Decho, 2000).

Biofilms consist of microorganisms embedded in a matrix of extracellular polymeric substances (EPS), which are produced by the different organisms of the biofilm. These EPS are chemically diverse molecules but are mainly composed of carbohydrates and protein, and contain very few lipids. EPS have various roles both for microorganisms: they protect from pollutants and desiccation (Decho, 1990; Potts, 1994) and they allow locomotion, especially for diatoms, and attachment to sediment (Wotton, 2004). They are also important for coastal systems, as they are for instance responsible for sediment stabilisation in intertidal areas (Decho, 1990).

Because their composition varies depending on their environment, microbial mats are useful as proxies of environmental conditions. Therefore, various markers have been developed to characterise the microbial composition of biofilms, and, more recently, their EPS composition. Quantification of carbohydrates and proteins has been a first step, and GCMS and LC-MS (gas and liquid chromatography coupled with mass spectrometry) now allow a further analysis of these molecules. Carbohydrates in particular have been investigated as they are crucial for sediment stabilisation by biofilms (de Brouwer et al., 2005); these 
molecules have been characterised through their monosaccharide composition, which has been shown to vary according to organisms and environmental conditions (de Brouwer and Stal, 2002; Hanlon et al., 2006; Underwood et al., 2004).

Due to the numerous roles of EPS in coastal systems, and given that these roles depend on EPS composition, characterising EPS composition and variations is an important challenge to understand the provision of ecosystem services by microbial mats in varying environments. Therefore, this study was designed to test the hypothesis that the EPS composition of biofilms: (1) varies seasonally and is influenced by other environmental conditions; and (2) does not only depend on the microorganisms forming the microbial mats. Biofilms were followed over the year on-field in an intertidal area, in three experimental conditions. Artificial tubes mimicking polychaete tubes were used to modify biofilm development, as such tubes influence both microbial expansion and EPS production (Passarelli et al., 2012). Biofilms were sampled monthly and the microbial assemblage was characterised by their fatty acid and pigment contents. EPS were characterised by the monosaccharide composition of their carbohydrates.

\title{
Material and methods
}

\author{
Study site \\ Experiments were carried out from March 2011 to April 2012 in the Chausey \\ archipelago (France) within the Normand-Breton Gulf (English Channel), which is \\ characterized by a megatidal regime (tidal range up to $14 \mathrm{~m}$ ). The Chausey archipelago \\ includes 1500 ha of soft sediment tidal flats.
}

\section{Experimental design}


Twelve cylindrical benthic chambers of $300 \mathrm{~mm}$ inner diameter and $60 \mathrm{~mm}$ depth were placed in the intertidal sandy area of Chausey archipelago (Normand-Breton Gulf, France). Solid PVC cylindrical rods were fixed to the bottom of each benthic chamber, simulating tubes of large polychaete "builder" species, such as Lanice conchilega or Melinna cristata (5 mm diameter, $95 \mathrm{~mm}$ length). Three treatments were used (4 replicate chambers per treatment); a control treatment (Ctrl), without tubes; then 2 test treatments with varying densities of evenly spaced tubes: a low density (LD) treatment $\left(637\right.$ tubes $\left.\cdot \mathrm{m}^{-2}\right)$ and a high density (HD) treatment $\left(2505\right.$ tubes $\left.\cdot \mathrm{m}^{-2}\right)$. The LD treatment potentially destabilised the sediment (i. e. initiated interactive flow; Friedrichs et al., 2000), whereas the HD treatment most likely had a stabilising effect on it (i. e. initiated skimming flow; Friedrichs et al., 2000). These densities were both within the range of natural densities for polychaete tubes (up to 5000 ind $\cdot \mathrm{m}^{-2}$; e.g. Friedrichs et al. 2000 for Melinna cristata).

Before positioning the chambers in the field, they were filled with defaunated sand (washed with $1 \mathrm{~mol} \cdot \mathrm{l}^{-1} \mathrm{HCl}$, frozen and thawed) collected at the study site (medium sand, median grain size between 260 and $300 \mu \mathrm{m}$ ). They were then placed into the intertidal area on 21 March 2011, with a 2 m gap between chambers. Sampling was carried out approximately every month (14 times in the experiment, depending on tidal height and accessibility of the study site) from the beginning of the experiment to 8 April 2012.

Sampling locations within the chambers were randomly chosen for each sampling time, taking care that a single location was never sampled twice in a 3-month period.

Visual observation of the plots confirmed that any cavities created by sampling were filled by natural sediment within $24 \mathrm{~h}$, after which no trace of the sampling was apparent.

\section{Sampling and measurements}


Fatty acids composition of the sediment

One sample was taken from each benthic chamber at every sampling date $(2 \mathrm{~cm}$ inner diameter cut off syringe, $1 \mathrm{~cm}$ depth). Sediment cores were frozen and transported back to the laboratory where they were freeze-dried, and stored at $-26^{\circ} \mathrm{C} .400$ to $500 \mathrm{mg}$ of sediment were weighted and used for the analysis. Fatty acid (FA) analysis was performed following the modified method of Bligh \& Dyer (1959) as described in Mortillaro et al. (2011). Before extraction, an internal standard (FA 23:0) was added to every sample for quantification purpose. Lipids were extracted with a 20 min ultrasonication in a mixture of distilled water, chloroform and methanol in ratio 1:1:2 (v:v:v). Lipids were concentrated under $\mathrm{N}_{2}$ flux, and saponified, in order to separate FAs, with a mixture of $\mathrm{NaOH}\left(2 \mathrm{~mol} \cdot \mathrm{l}^{-1}\right)$ and methanol $(1: 2$, v:v) at $90{ }^{\circ} \mathrm{C}$ during $90 \mathrm{~min}$. Saponification was stopped with hydrochloric acid. FAs were then derivatized with $\mathrm{BF}_{3}$-methanol (boron-trifluoride methanol) at $90{ }^{\circ} \mathrm{C}$ during $10 \mathrm{~min}$ and kept frozen in chloroform. Just before analysis, samples were dried under $\mathrm{N}_{2}$ flux and transferred to hexane. One $\mu 1$ of the mixture was injected in a gas chromatograph (GC, Varian CP-3800 equipped with flame ionization detector), which allowed separation and quantification of FAs. Separation was performed with a Supelco OMEGAWAX 320 column (30 $\mathrm{m} \times 0.32 \mathrm{~mm}$ i.d., $0.25 \mu \mathrm{m}$ film thickness) with He as carrier gas. The following temperature program was used: $60^{\circ} \mathrm{C}$ for $1 \mathrm{~min}$, then raise to $150{ }^{\circ} \mathrm{C}$ at $40^{\circ} \mathrm{C} \cdot \mathrm{min}^{-1}$ (held $3 \mathrm{~min}$ ), then raise to $240{ }^{\circ} \mathrm{C}$ at $3{ }^{\circ} \mathrm{C} \cdot \mathrm{min}^{-1}$ (held $7 \mathrm{~min}$ ). Peaks of FAs were identified by comparison of the retention time with analytical standards (Supelco ${ }^{\mathrm{TM}}$ 37, PUFA-1 Marine Source, and Bacterial Mix, Supelco Inc., USA) and analysis of the sample in a gas chromatograph coupled to mass spectrometer (GC-MS, Varian 450GC with Varian 220-MS).

FAs are designated as $\mathrm{X}: \mathrm{Y} \omega \mathrm{Z}$, where $\mathrm{X}$ is the number of carbons, $\mathrm{Y}$ the number of double bonds and $\mathrm{Z}$ the position of the ultimate double bond from the terminal methyl. 


\section{$\underline{\text { Pigment composition of the sediment }}$}

Three samples were taken from each benthic chamber at every sampling date $(2 \mathrm{~cm}$ inner diameter cut off syringe, $1 \mathrm{~cm}$ depth), and pooled. Samples were kept frozen at $-26{ }^{\circ} \mathrm{C}$ until analysis. Pigments were extracted from a sub-sample of approximately $0.2 \mathrm{~g}$ of freezedried sediment with $2 \mathrm{ml}$ of $95 \%$ cold buffered methanol ( $2 \%$ ammonium acetate) for $15 \mathrm{~min}$ at $-20{ }^{\circ} \mathrm{C}$, in the dark. Samples were sonicated for $30 \mathrm{~s}$ at the beginning of the extraction period. Extracts were filtered with Whatman membrane filters $(0.2 \mathrm{~mm})$ immediately before HPLC analysis. Pigment extracts were analysed using a Shimadzu HPLC comprised of a solvent delivery module (LC-10ADVP) with system controller (SCL-10AVP), a photodiode array (SPD-M10AVP) and a fluorescence detector (RF-10AXL). Chromatographic separation was carried out using a C18 column for reverse phase chromatography (Supelcosil, $25 \mathrm{~cm}$ long, $4.6 \mathrm{~mm}$ in diameter, and $5 \mu \mathrm{m}$ particles). The solvents used were $0.5 \mathrm{~mol} \cdot \mathrm{l}^{-1}$ ammonium acetate in methanol and water (85:15, v:v), acetonitrile and water (90:10, v:v), and $100 \%$ ethyl acetate. The solvent gradient followed Kraay et al. (1992) with a flow rate of $0.6 \mathrm{ml} \cdot \mathrm{min}^{-1}$ and an injection volume of $100 \mu \mathrm{l}$. Identification and calibration of the HPLC peaks was confirmed with chlorophyll $a$, chlorophyll $b$ and b-carotene standards from Sigma and chlorophyll $c$, fucoxanthin, diadinoxanthin , diatoxanthin, lutein, zeaxanthin, and pheophytin $a$ standards from DHI. Pigments were identified by the absorption spectra and retention times and the concentrations calculated from the signals in the photodiode array (chlorophylls and carotenoids) or fluorescence detector (pheophorbides and pheophythins). As samples were not frozen in situ but transported in the dark before being frozen, diatoxanthin had time to revert to diadinoxanthin. Therefore, concentrations of diatoxanthin and diadinoxanthin were added and analysed together as xanthophyll concentration.

\section{$\underline{\text { EPS composition in monosaccharides }}$}


Three samples were taken from each benthic chamber at every sampling date $(2 \mathrm{~cm}$ inner diameter cut off syringe, $1 \mathrm{~cm}$ depth), pooled onto one sample per chamber, and frozen until analysis. Monosaccharide composition of carbohydrates was determined using gas chromatography (GC), following a method adapted from Pierre et al. (2010). Briefly, EPS were extracted, and carbohydrates decomposed into monosaccharides with acidic hydrolysis. Sugars were thereafter silylated and separated with GC.

Colloidal EPS were extracted by rotating the samples in artificial sea water $\left(30 \mathrm{~g} \cdot \mathrm{l}^{-1}\right)$ $1 \mathrm{~h}$ at $4{ }^{\circ} \mathrm{C}$. Bound EPS were thereafter recovered by adding resin (Dowex Marathon C, sodium form, Sigma) to the remaining sediment and performing a second extraction. Both fractions were dialysed against distilled water $(12-14 \mathrm{kDa})$ and freeze-dried.

EPS were dissolved in $2 \mathrm{~mol} \cdot \mathrm{l}^{-1} \mathrm{HCl}$, and heated $4 \mathrm{~h}$ at $90{ }^{\circ} \mathrm{C}$. The solution then mainly contained monosaccharides, and was freeze-dried again.

Silylation was performed with a mixture of BSTFA:TMCS (N,Obis(trimethylsilyl)trifluoroacetamide and trimethylchlorosilane, 100:1, Sigma) and pyridine $(1: 1, \mathrm{v}: \mathrm{v}), 2 \mathrm{~h}$ at room temperature. After the silylation, $1 \mu \mathrm{l}$ of the sample was injected in GC (GC, Varian CP-3800 equipped with flame ionization detector), which allowed separation and relative quantification of sugars. Separation was performed with an Agilent Technologies VF$1701 \mathrm{~ms}$ column $(30 \mathrm{~m} \times 0.32 \mathrm{~mm}$ i.d., $0.25 \mu \mathrm{m}$ film thickness $)$ with He as carrier gas. The following temperature program was used: start at $150{ }^{\circ} \mathrm{C}$, raise to $200{ }^{\circ} \mathrm{C}$ at $7{ }^{\circ} \mathrm{C} \cdot \mathrm{min}^{-1}$ (held $5 \mathrm{~min}$ ). Injector temperature was set at $250^{\circ} \mathrm{C}$. Peaks of monosaccharides were identified by comparison of the retention time with analytical standards (rhamnose, fucose, xylose, mannose, galactose, glucose, scyllo- and myo-inositol, galacturonic and glucuronic acid), which had been prepared (silylation and injection only) as samples.

Carbohydrate and protein concentrations in EPS were measured by colorimetry following methods from Lubarsky et al. (2010). 


\section{Statistical analyses}

Non-parametric statistics under the R statistical framework were used for univariate analyses as data violated assumptions of homogeneity of variance and normality. Differences between treatments were assessed by Kruskal-Wallis tests (KW), while differences between sampling time for each treatment were assessed by Friedman tests (considering data from each chamber as paired data).

Non-metric MultiDimensional Scaling (nMDS) analyses (500 iterations) were performed with similarity matrix constructed with Bray Curtis distances for FAs, pigments and sugars. These graphical representations show similarity between samples: the closer the symbols are in the representation, the closer the characteristics of the samples are. 2-factor ANOSIMs (crossed factors: Time and Treatments) were then used to assess the difference between assemblages from different sampling time (Primer 5 software, 10000 iterations), and variables responsible for such differences were investigated with SIMPER analyses.

Multiple Factor Analysis (MFA) was performed to compare chambers at different sampling time using FA, pigment and sugar datasets. MFA studies several groups of variables defined on the same set of individuals. The core of the method is a factor analysis applied to the whole set of variables, in which each group of variables is weighted so that no group of variables become dominant over the others (Escofier and Pagès, 1994). Data were scaled to unit variance.

\section{Results}

\section{Composition of the microbial community}

$\underline{\text { Fatty acid contents }}$ 
Overall compositions of microbial communities and organic matter in sediment was assessed through their fatty acid (FA) content. Quantitative data (Fig. S1) showed accumulation of FAs in sediment in early August and late September. FAs found in our sediment samples are listed on table S1. Most abundant FAs were saturated FAs (SFAs) 14:0, 16:0, 18:0, mono-unsaturated FA (MUFA) 16:1 17 and polyunsaturated FA (PUFA) 20:5 $\omega 3$, suggesting a large abundance of diatoms in these biofilms. Moreover, branched FAs (BFAs) reached a $2 \%$ relative contribution, showing the presence of heterotrophic bacteria.

Data showed a dramatic change in FA composition of sediment through time (Fig. 1; ANOSIM: $\mathrm{R}=0.767, p<0.001)$. Samples from two following months were significantly different one from each other's, except in winter where samples were similar (ANOSIM post-

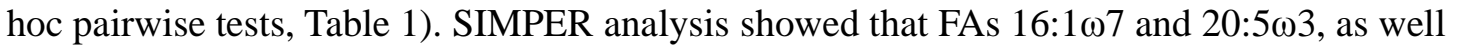
as saturated FAs (SFAs; mainly 14:0, 16:0 and 18:0) were responsible for the differences

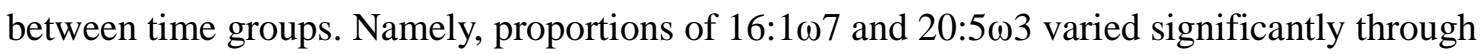
time in every treatment (Friedman tests, $p<0.001$ ); they were present in higher proportions in April, May, at the beginning of August, in some samples of November and from January to March 2012, compared to other months. On the contrary, the ratio between saturated and polyunsaturated FAs (SFA/PUFA ratio) was lower in these months.

Samples were also significantly different between treatments (ANOSIM, R $=0.284$, $\mathrm{p}<0.001 ;$ ANOSIM post-hoc pairwise tests Table 2), although the time effect seemed

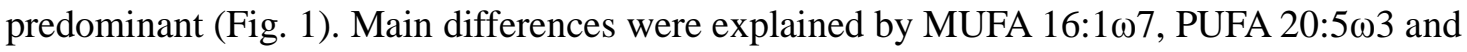
SFA 18:0, which were more abundant in Ctrl treatments compared to others; by SFA 14:0 which was more abundant in both treatments with tubes; and by SFA 16:0 which accumulated more in LD chambers.

\section{$\underline{\text { Pigment contents }}$}


Overall composition of the photosynthetic communities in sediment was assessed through their pigment content. Total pigment concentrations (Fig. S1) showed accumulation in summer (LD treatments) or after summer (other treatments). Sediment samples contained mainly chlorophyll $a$, fucoxanthin, alloxanthin and chlorophyll $c$ (Table S2), showing the preponderance of diatoms and cryptophytes.

Pigment composition of sediment also changed through time (Fig. 2; ANOSIM: $\mathrm{R}=0.393, \mathrm{p}<0.001)$. Significant differences between two following month mostly appear in late summer, at the beginning of autumn and in winter (ANOSIM post-hoc pairwise tests, Table 1). Regardless of the sampling time, chlorophyll $a$ accounted for approximately $50 \%$ of pigments in sediment, while proportions of fucoxanthin and alloxanthin exhibited significant differences among time (Friedman tests, $p>0.05$ for chlorophyll $a$ and $p<0.05$ for fucoxanthin and alloxanthin). Pigments contributing highly to dissimilarities between seasons were chlorophylls $a$ and $c$, which were in higher proportions in autumn and winter, and chlorophyllide $a$ and xanthophylls, which were in higher proportions in spring and summer.

Pigment composition of sediment changed weakly between treatments (ANOSIM: $\mathrm{R}=0.08, \mathrm{p}=0.016)$ : chambers with tubes had significantly different compositions compared to control chambers (ANOSIM post-hoc pairwise tests, Table 2). Chlorophyllide $a$ was indeed in lower proportion and alloxanthin in higher proportion in Ctrl chambers compared to other chambers.

\section{EPS}

\section{$\underline{\text { General composition }}$}

EPS total concentrations in both carbohydrates and proteins showed variations through time, with accumulation of EPS at the beginning of summer (Fig. S3). Glucose was the most abundant sugar, followed by mannose and galactose (Table S3). Glucose percentages varied 
significantly through time in each treatment, for colloidal and bound fractions (Friedman tests, $p<0.001$ ), with highest contributions in summer.

$\underline{\text { EPS fractions }}$

Colloidal and bound fractions had slightly different monosaccharide compositions (ANOSIM: $\mathrm{R}=0.083, p<0.001$ ). SIMPER analysis showed that 4 sugars explained more than $70 \%$ of dissimilarities between fractions: glucose was more abundant in colloidal EPS while mannose, xylose and scyllo-inositol were more abundant in bound EPS.

Therefore, the analysis was made separately for colloidal and bound EPS fractions.

\section{Colloidal EPS}

Monosaccharide composition of colloidal EPS changed through time, with significant differences between sampling months (Fig. 3; ANOSIM: $\mathrm{R}=0.375, p<0.001$ ). Periods of variations were distributed along the year (ANOSIM post-hoc tests, Table 1). Sugars explaining most dissimilarity between sampling times were the most abundant: glucose, mannose and galactose, as well as scyllo-inositol when comparing winter months with other sampling times.

No significant differences between treatments were found (ANOSIM, $R=0.049$, $\mathrm{p}=0.068)$.

\section{Bound EPS}

Monosaccharide composition of bound EPS changed through time, with significant differences between sampling months (Fig. 4; ANOSIM, $\mathrm{R}=0.376, p<0.001$ ). Significant evolution of bound EPS composition was mainly found between August and February (Table 
1). Sugars explaining most dissimilarity between sampling times were also glucose, mannose and galactose.

Bound EPS composition in monosaccharides also changed slightly between treatments (ANOSIM: $\mathrm{R}=0.079, \mathrm{p}=0.017$ ): $\mathrm{Ctrl}$ and $\mathrm{LD}$ had significantly different compositions compared to HD chambers (ANOSIM post-hoc pairwise tests, Table 2).

\section{Multi-marker approach}

Results of MFA combining datasets of FAs, pigments, colloidal and bound EPS are displayed in Fig. 8. Glucose and galactose percentages in both EPS fractions contribute most to the first axis, while pigments $\beta$-caroten, xanthophylls, pheophytin, percentage of myoinositol in bound EPS, and FA 16:1 107 contribute most to the second axis. Results showed correlations between different types of variables (Fig. 5.A); for instance, pigment pheophytin $a$ was associated with most of branched FAs. Combination of the four datasets allowed the segregation of samples from different months along a clear seasonal cycle, with a specific combination of biomarkers for each season (Fig 5.B).

\section{Discussion}

\section{EPS composition over the course of the experiment}

\section{$\underline{\text { Composition of carbohydrates in colloidal and bound EPS }}$}

EPS were divided in two fractions according to their extraction protocol: the colloidal fraction was extracted with water only whereas bound EPS were collected with a strong cationic resin (Takahashi et al., 2009). This resin traps the cations maintaining the links between bound EPS, therefore allowing their release in the water. Our results demonstrate that these two EPS fractions are chemically different, as their monosaccharide general 
compositions are significantly different. These two compositions of colloidal and bound EPS do not change simultaneously along the year (Table 1), suggesting that their control is specific to each EPS fraction. These different compositions are consistent with literature data showing that both fractions have different production and degradation pathways (Staats et al., 1999; Underwood and Paterson, 2003).

Most abundant sugars were the same, but in different proportions, in both fractions. EPS carbohydrates consisted mostly in glucose, which always reached percentages over $50 \%$. Colloidal EPS contained more glucose than bound EPS, which is consistent with literature data (Hofmann et al., 2009; Pierre et al., 2010; Taylor et al., 1999). Yet, Pierre et al. (2010) obtained lower percentages of glucose, especially in bound fractions were percentage reached $20 \%$ of total monosaccharide only. This difference could originate from a different producing community, for instance epipelic assemblages instead of epipsammic ones, as they analysed

mud instead of sand in our study. Also, our sampling protocol, which includes a freezing step, might prompt release of intracellular material, especially of some chrysolaminarin, which is an intracellular storage glucan in diatoms, mainly composed of glucose (Chiovitti et al., 2004; Underwood et al., 2004). Other abundant monosaccharides were mannose and galactose, which is consistent with observation made on Cylindrotheca closterium cultures (Underwood et al., 2004). Yet, the large amounts of glucose, mannose and galactose present in our sediment samples suggest that organic matter was mostly fresh, as these three sugars are particularly labile (Oakes et al., 2010).

\section{$\underline{\text { Variations in EPS compositions }}$}

Both bound and colloidal carbohydrates displayed seasonal variations in their monosaccharide composition. Glucose was mainly responsible for seasonal differences; it accumulated in summer and was recorded in lower proportions in other seasons. Higher percentages of glucose in EPS have been correlated with photosynthetic production (Bellinger 
et al., 2005; de Brouwer and Stal, 2001; Hanlon et al., 2006). Also, in the studied sediments, the increase in glucose proportion in summer may originate from the degradation of intracellular chrysolaminarin, released in the environment by senescent diatoms. Other seasons displayed a higher diversity of sugars, which could be explained by the preferential degradation of glucose by heterotrophic bacteria (Bellinger et al., 2005; Hofmann et al., 2009): particularly, fucose, rhamnose and galactose are known to be more difficult for them to assimilate than glucose (Giroldo et al., 2003). Finally, nutrient concentrations in pore water and light exposure of biofilms also vary seasonally, and both factors have been demonstrated to alter EPS carbohydrate composition (de Brouwer and Stal, 2002; Underwood et al., 2004), potentially strengthening the effects of photosynthesis and EPS degradation in shaping carbohydrate composition.

Colloidal EPS compositions were not influenced by experimental conditions, while the composition of bound carbohydrates appeared to vary between treatments: chambers with high tube density had different sediment composition compared to others chambers. Such effect might result from a direct influence of hydrodynamics on EPS production, or from an indirect influence of tubes on benthic assemblages, or from a combination of both. As microbial assemblages and bound EPS compositions do not display similar temporal evolutions (Table 1), a direct effect of hydrodynamics on the production or degradation of bound EPS is a likely hypothesis. With such mechanisms, microorganisms could better adapt their adhesion to the local current conditions. For instance, desoxy-monosaccharides like rhamnose and pentoses like xylose are able to promote adhesion to sediment because of their hydrophobicity (Bellinger et al., 2009).

\section{$\underline{\text { Functionality of different sugars }}$}

Pierre et al. (2010) revealed the presence of myo-inositol in carbohydrates of marine sediment; this sugar is crucial for the functioning of many eukaryotic cells and is also a 
growth factor for various organisms. Our sediment samples also contained this sugar, and additionally its stereoisomer: scyllo-inositol. To our knowledge, this monosaccharide has never been found in EPS carbohydrates. In diatoms, it may originate from myo-inositol after transformation by the myo-inositol deshydrogenase enzyme (Gross and Meyer, 2003), which may explain its presence in the biofilm. Also, this monomer was an important sugar in separating winter from other seasons, which might be explained by variations in the functioning of this enzyme, although its role is still under investigation (Gross and Meyer, 2003). In soils, scyllo-inositol is associated to phosphate in scyllo-inositol hexakisphosphate, which forms an important part of the organic phosphorus content (Turner et al., 2005).

When studying different mudflats, de Brouwer et al. (2003) showed that EPS mainly originated from refractory dissolved organic matter. This is probably not the case here, as monosaccharide composition revealed a high proportion of glucose in every sample. Sugar composition can therefore be interpreted in terms of functionality for microorganisms. For instance, uronic acids have acidic groups which provide sites for sediment - organism interactions, so that they facilitate the fixation of cells to sediment (Bellinger et al., 2009). Also, deoxy-sugars such as fucose and rhamnose, and pentoses seem to promote biostabilisation of the sediment by enhancing the hydrophobicity of the biofilm (Bellinger et al., 2009; Zhou et al., 1998). Finally, differences in monosaccharide composition have been shown to promote the development of different bacterial communities, depending on the ability of different bacterial groups to degrade these carbohydrates (Taylor et al., 2013). Changes in EPS composition and bacterial population will in turn provide recruitment cues for diverse organisms and can therefore facilitate or hinder the resilience of ecosystem engineers (Nelson et al., 2013).

\section{EPS and microbial communities}




\section{$\underline{\text { Fatty acid biomarkers }}$}

In the studied environment, external factors varying seasonally such as temperature, photoperiod, and hydrodynamics have a strong structuring influence on EPS composition. EPS composition is also impacted by the composition of producing assemblages (Decho, 1990), which were in the present work characterised by their fatty acid (FA) and pigment compositions. FAs ubiquitous to all living organisms, but most taxonomic or functional groups are characterised by a given association of some FAs. For instance, branched FAs are only produced by bacteria (Arts and Wainman, 1999). Description of FA content of sediment provides, together, information on taxonomic or functional groups and on the degradation state of organic matter. The increase of SFA percentages, and of its ratio to PUFAs, demonstrates an accumulation of degraded OM in sediments in summer and autumn (Grossi et al., 2006; Sun et al., 1997). On the other hand, spring and winter months, as well as the beginning of August, are characterised by higher MUFA and PUFAs percentages; in

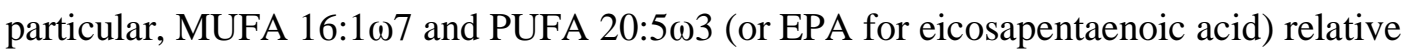
contributions showed a drastic increase in these months. These FAs are mainly produced by microphytobenthos in these environments, especially diatoms, dinoflagellates and cyanobacteria (Arts and Wainman, 1999; Volkman et al., 1980). Yet the association of MUFA 16:1 17 and PUFA 20:5 13 together with high amounts of SFAs 14:0 and 16:0 suggest a dominance of diatoms (Dijkman et al., 2010).

\section{$\underline{\text { Pigment biomarkers }}$}

Pigments were used to characterise the abundance and taxonomic composition of microphytobenthic communities. The abundance of fucoxanthin, together with chlorophylls $a$ and $c$, is consistent with results of FA analysis in demonstrating the prevalence of diatoms in this environment (Jeffrey et al., 1997). Also, the presence of alloxanthin shows the occurrence of cryptophytes (Jeffrey et al., 1997). Proportions of chlorophylls $c$ and fucoxanthin displayed 
a seasonal pattern, being higher in autumn and winter compared to spring and summer; on the contrary, chlorophyllide $a$ showed a reversed pattern. This last pigment reveals the occurrence of senescent diatoms (Jeffrey et al., 1999), which suggests a higher predation rate in these months. Also, the occurrence of chlorophyllide $a$ might be related to an exogenous supply of pigment. Xanthophylls displayed the same seasonal pattern than chlorophyllide $a$, which can be explained by their role in the xanthophyll cycle, which act as a photoprotection mechanism (Jeffrey et al., 1997); in spring and summer months, when light intensity increases, xanthophyll production increases, and diadinoxanthin in transformed into diatoxanthin.

\section{Multi-marker approach and general dynamic of the biofilm}

When combining datasets of FAs and pigments together with those on EPS composition (Fig. 5), samples from every month clearly gathered together, showing a welldefined temporal evolution. Also, this analysis highlights the association between variables and samples, which allows following the dynamics of the biofilm in the course of year and to link EPS composition with microorganisms.

In winter time, the sediment contained high proportions of fucoxanthin and chlorophyll $c$, which indicated the development of diatoms (Jeffrey et al., 1997); in the meantime, proportions of most sugars except glucose, particularly galactose and mannose in both EPS fractions, and scyllo-inositol in colloidal EPS, increased. In spring, the abundance

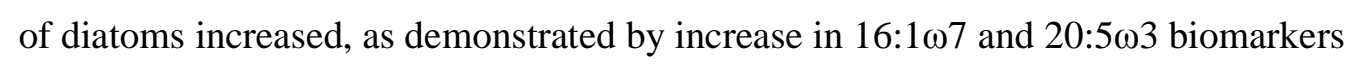
(Dalsgaard et al., 2003). Also, the increase of alloxanthin proportions together with 18:403 FAs mirrored the development of cryptophytes. In late spring, xanthophyll proportions increased, as a protection against light intensity for diatoms (Jeffrey et al., 1997). Summer was characterised by high amounts of most saturated FAs, which indicates the accumulation of degraded organic matter (Balzano et al., 2011; Lü et al., 2010; Sun et al., 1997). This degradation is emphasised by the presence of chlorophyllide $a$ which indicates the presence of 
senescing diatoms (Jeffrey et al., 1999); these organisms may then release in the environment high amounts of intracellular chrysolaminarin, explaining the increase of glucose proportions in both EPS fraction in summer. Some glucose may also originate from higher photosynthetic production in late spring and in the beginning of summer, when light intensity, photoperiod and temperature increase. Finally, autumn is characterised by high levels of markers of bacterial degradation: pheophytin $a$ which results from the degradation of chlorophyll (Lorenzen, 1967) as well as most branched FAs, which characterise heterotrophic bacteria (Arts and Wainman, 1999).

Results of analyses on separate datasets showed no correlation between the periods where microbial assemblages change and those where EPS composition does so (Table 1). However, our multi-marker analysis suggested links between EPS composition and biological processes taking place in the sediment, such as photosynthesis, which depend on microbial assemblages. For instance, the large increase of glucose contribution in summer was linked to the degradation of senescing diatoms evidenced by chlorophyllide $a$. Finally, it seems that EPS composition of sediment is influenced at the same time by the succession of microbial assemblages taking place in tidal flats and directly by environmental conditions.

\section{$\underline{\text { Conclusion }}$}

In this study, association of FA and pigment biomarkers together with monosaccharide composition of EPS complemented each other to allow a fine characterisation of the biofilm in the course of year, describing its composition and functioning. Furthermore, as different monosaccharides may be associated with different ecosystem functions (stabilisation, recruitment cues for instance; Bellinger et al., 2009; Nelson et al., 2013; Zhou et al., 1998), this set of variables may indicate diverse roles of biofilms for the ecosystem. 


\section{Acknowledgment}

The authors thank two anonymous reviewers whose advice and comments greatly improved the manuscript. We the Conservatoire du Littoral, the Syndicat Mixte des Espaces Littoraux de la Manche and the Syndicat Mixte Littoral Normand for their involvement in the project. We thank M.-F. Bernard, Y. Turgis, A. Guigny, E. Oulhen, A. Migné and the crew of Gwen Ha Ruz for their valuable help with fieldwork. This work received support from the “ATM Biodiversité des microorganismes", and their support is gratefully acknowledged. 


\section{References}

Arts, M.T., Wainman, B.C., 1999. Lipids in Freshwater Ecosystems. Springer-Verlag, New York.

Balzano, S., Pancost, R.D., Lloyd, J.R., Statham, P.J., 2011. Changes in fatty acid composition in degrading algal aggregates. Mar. Chem. 124, 2-13.

Bellinger, B.J., Abdullahi, A.S., Gretz, M.R., Underwood, G.J.C., 2005. Biofilm polymers: relationship between carbohydrate biopolymers from estuarine mudflats and unialgal cultures of benthic diatoms. Aquat. Microb. Ecol. 38, 169-180.

Bellinger, B.J., Underwood, G.J.C., Ziegler, S.E., Gretz, M.R., 2009. Significance of diatomderived polymers in carbon flow dynamics within estuarine biofilms determined through isotopic enrichment. Aquat. Microb. Ecol. 55, 169-187.

Bligh, E.G., Dyer, W.J., 1959. A rapid method of total lipid extraction and purification. Can. J. Biochem. Physiol. 37, 911-917.

Brotas, V., Cabrita, T., Portugal, A., Serodio, J., Catarino, F., 1995. Spatio-temporal distribution of the microphytobenthic biomass in intertidal flats of Tagus Estuary (Portugal). Hydrobiologia 300, 93-104.

Chiovitti, A., Molino, P., Crawford, S.A., Teng, R.W., Spurck, T., Wetherbee, R., 2004. The glucans extracted with warm water from diatoms are mainly derived from intracellular chrysolaminaran and not extracellular polysaccharides. Eur. J. Phycol. 39, 117-128.

Dalsgaard, J., St John, M., Kattner, G., Muller-Navarra, D., Hagen, W., 2003. Fatty acid trophic markers in the pelagic marine environment. Adv. Mar. Biol. 46, 225-340. de Brouwer, J.F.C., de Deckere, E., Stal, L.J., 2003. Distribution of extracellular carbohydrates in three intertidal mudflats in Western Europe. Estuar. Coast. Shelf. Sci. 56, 313-324. 
de Brouwer, J.F.C., Stal, L.J., 2001. Short-term dynamics in microphytobenthos distribution and associated extracellular carbohydrates in surface sediments of an intertidal mudflat. Mar. Ecol.-Prog. Ser. 218, 33-44.

de Brouwer, J.F.C., Stal, L.J., 2002. Daily fluctuations of exopolymers in cultures of the benthic diatoms Cylindrotheca closterium and Nitzschia sp. (Bacillariophyceae). J. Phycol. $38,464-472$.

de Brouwer, J.F.C., Wolfstein, K., Ruddy, G.K., Jones, T.E.R., Stal, L.J., 2005. Biogenic stabilization of intertidal sediments: The importance of extracellular polymeric substances produced by benthic diatoms. Microb. Ecol. 49, 501-512.

Decho, A.W., 1990. Microbial exopolymer secretions in ocean environments: their role(s) in food webs and marine processes, in: Barnes, M. (Ed.), Oceanography and Marine Biology: an Annual review. Aberdeen University Press, pp. 73-153.

Decho, A.W., 2000. Microbial biofilms in intertidal systems: an overview Cont. Shelf Res. $20,1257-1273$.

Dijkman, N.A., Boschker, H.T.S., Stal, L.J., Kromkamp, J.C., 2010. Composition and heterogeneity of the microbial community in a coastal microbial mat as revealed by the analysis of pigments and phospholipid-derived fatty acids. J. Sea Res. 63, 62-70.

Escofier, B., Pagès, J., 1994. Multiple factor analysis (AFMULT package). Computational Statistics \& Data Analysis 18, 121-140.

Franks, J., Stolz, J.F., 2009. Flat laminated microbial mat communities. Earth-Sci. Rev. 96, $163-172$.

Friedrichs, M., Graf, G., Springer, B., 2000. Skimming flow induced over a simulated polychaete tube lawn at low population densities. Mar. Ecol.-Prog. Ser. 192, 219-228. 
Giroldo, D., Vieira, A.A.H., Paulsen, B.S., 2003. Relative increase of deoxy sugars during microbial degradation of an extracellular polysaccharide released by a tropical freshwater Thalassiosira sp (Bacillariophyceae). J. Phycol. 39, 1109-1115.

Gross, W., Meyer, A., 2003. Distribution of myo-inositol dehydrogenase in algae. Eur. J. Phycol. 38, 191-194.

Grossi, V., Cuny, P., Caradec, S., Nerini, D., Pancost, R., Gilbert, F., 2006. Impact of feeding by Arenicola marina (L.) and ageing of faecal material on fatty acid distribution and bacterial community structure in marine sediments: An experimental approach. J. Exp. Mar. Biol. Ecol. $336,54-64$.

Hanlon, A.R.M., Bellinger, B., Haynes, K., Xiao, G., Hofmann, T.A., Gretz, M.R., Ball, A.S., Osborn, A.M., Underwood, G.J.C., 2006. Dynamics of extracellular polymeric substance (EPS) production and loss in an estuarine, diatom-dominated, microalgal biofilm over a tidal emersion-immersion period. Limnol. Oceanogr. 51, 79-93.

Hofmann, T.A., Hanlon, A.R.M., Taylor, J.D., Ball, A.S., Osborn, A.M., Underwood, G.J.C., 2009. Dynamics and compositional changes in extracellular carbohydrates in estuarine sediments during degradation. Mar. Ecol.-Prog. Ser. 379, 45-58.

Jeffrey, S.W., Mantoura, R.F.C., Wright, S.W., 1997. Phytoplankton pigments in oceanography: guidelines to modern methods. UNESCO, Paris.

Jeffrey, S.W., Wright, S.W., Zapata, M., 1999. Recent advances in HPLC pigment analysis of phytoplankton. Mar. Freshw. Res. 50, 879-896.

Kraay, G.W., Zapata, M., Veldhuis, M.J.W., 1992. Separation of chlorophylls $c 1, c 2$ and $c 3$ of marine phytoplankton by reversed-phase-C18-high-performance liquid chromatography. J. Phycol. 28, 708-712.

Lorenzen, C.J., 1967. Determination of Chlorophyll and Pheo-Pigments: Spectrophotometric Equations. Limnol. Oceanogr. 12, 343-346. 
Lü, D., Song, Q., Wang, X., 2010. Decomposition of algal lipids in clay-enriched marine sediment under oxic and anoxic conditions. Chin. J. Oceanol. Limnol. 28, 131-143. Lubarsky, H.V., Gerbersdorf, S.U., Hubas, C., Behrens, S., Ricciardi, F., Paterson, D.M., 2012. Impairment of the Bacterial Biofilm Stability by Triclosan. PLoS One 7, e31183. Lubarsky, H.V., Hubas, C., Chocholek, M., Larson, F., Manz, W., Paterson, D.M., Gerbersdorf, S.U., 2010. The stabilisation potential of individual and mixed assemblages of natural bacteria and microalgae. PLoS One 5, e13794.

Mortillaro, J.M., Abril, G., Moreira-Turcq, P., Sobrinho, R.L., Perez, M., Meziane, T., 2011. Fatty acid and stable isotope $(\delta 13 \mathrm{C}, \delta 15 \mathrm{~N})$ signatures of particulate organic matter in the lower Amazon River: Seasonal contrasts and connectivity between floodplain lakes and the mainstem. Org. Geochem. 42, 1159-1168.

Nelson, C.E., Goldberg, S.J., Wegley Kelly, L., Haas, A.F., Smith, J.E., Rohwer, F., Carlson, C.A., 2013. Coral and macroalgal exudates vary in neutral sugar composition and differentially enrich reef bacterioplankton lineages. ISME J. 7, 962-979.

Oakes, J.M., Eyre, B.D., Middelburg, J.J., Boschker, H.T.S., 2010. Composition, production, and loss of carbohydrates in subtropical shallow subtidal sandy sediments: Rapid processing and long-term retention revealed by C-13-labeling. Limnol. Oceanogr. 55, 2126-2138.

Passarelli, C., Olivier, F., Paterson, D.M., Hubas, C., 2012. Impacts of biogenic structures on benthic assemblages: microbes, meiofauna, macrofauna and related ecosystem functions. Mar. Ecol. Prog. Ser. 465, 85-97.

Paterson, D.M., Hagerthey, S.E., 2001. Microphytobenthos in Contrasting Coastal Ecosystems: Biology and Dynamics, in: Reise, K. (Ed.), Ecological Comparisons of Sedimentary Shores. Springer. 
Pierre, G., Graber, M., Orvain, F., Dupuy, C., Maugard, T., 2010. Biochemical

characterization of extracellular polymeric substances extracted from an intertidal mudflat

using a cation exchange resin. Biochem. Syst. Ecol. 38, 917-923.

Potts, M., 1994. Desiccation Tolerance of Prokaryotes. Microbiol. Rev. 58, 755-805.

Sawall, Y., Richter, C., Ramette, A., 2012. Effects of Eutrophication, Seasonality and

Macrofouling on the Diversity of Bacterial Biofilms in Equatorial Coral Reefs. PLoS One 7, e39951.

Staats, N., De Winder, B., Stal, L.J., Mur, L.R., 1999. Isolation and characterization of extracellular polysaccharides from the epipelic diatoms Cylindrotheca closterium and Navicula salinarum. Eur. J. Phycol. 34, 161-169.

Sun, M.Y., Wakeham, S.G., Lee, C., 1997. Rates and mechanisms of fatty acid degradation in oxic and anoxic coastal marine sediments of Long Island Sound, New York, USA. Geochim. Cosmochim. Acta 61, 341-355.

Takahashi, E., Ledauphin, J., Goux, D., Orvain, F., 2009. Optimising extraction of extracellular polymeric substances (EPS) from benthic diatoms: comparison of the efficiency of six EPS extraction methods. Mar. Freshw. Res. 60, 1201-1210.

Taylor, I.S., Paterson, D.M., Mehlert, A., 1999. The quantitative variability and monosaccharide composition of sediment carbohydrates associated with intertidal diatom assemblages. Biogeochemistry 45, 303-327.

Taylor, J.D., Mc Kew, B.A., Kuhl, A., McGenity, T.J., Underwood, G.J.C., 2013. Microphytobenthic extracellular polymeric substances (EPS) in intertidal sediments fuel both generalist and specialist EPS-degrading bacteria. Limnol. Oceanogr. 58, 1463-1480. Turner, B.L., Mahieu, N., Condron, L.M., Chen, C.R., 2005. Quantification and bioavailability of scyllo-inositol hexakisphosphate in pasture soils. Soil Biol. Biochem. 37, $2155-2158$. 
Underwood, G.J.C., Boulcott, M., Raines, C.A., Waldron, K., 2004. Environmental effects on exopolymer production by marine benthic diatoms: Dynamics, changes in composition, and pathways of production. J. Phycol. 40, 293-304.

Underwood, G.J.C., Paterson, D.M., 2003. The Importance of Extracellular Carbohydrate Production by Marine Epipelic Diatoms. Adv. Bot. Res. 40, 183-239.

Volkman, J.K., Johns, R.B., Gillan, F.T., Perry, G.J., Bavor, H.J., 1980. Microbial lipids of an inter-tidal sediment. 1. Fatty-acids and hydrocarbons. Geochim. Cosmochim. Acta 44, 11331143.

Wotton, R.S., 2004. The essential role of exopolymers (EPS) in aquatic systems, in: Gibson, R.N., Atkinson, R.J.A., Gordon, J.D.M. (Eds.), Oceanography and Marine Biology: an Annual Review. Aberdeen University Press, pp. 57-94.

Zhou, J., Mopper, K., Passow, U., 1998. The role of surface-active carbohydrates in the formation of transparent exopolymer particles by bubble adsorption of seawater. Limnol. Oceanogr. 43, 1860-1871. 
1 Table 1: Results of ANOSIM pairwise post-hoc tests comparing consecutive months (e. g. May with April and June) using 4 sets of markers:

2 fatty acids, pigments, colloidal and bound sugars. All 12 samples (pooled from all 3 treatments) from each sampling times were used. Test

3 significance: ns: not significant; *: $\mathrm{p}<0.05 ; * * \mathrm{p}<0.01$; **: $\mathrm{p}<0.001$. Coll: colloidal. Aug: August; Sept: September; Oct: October; Nov:

4 November; Jan: January; Feb: February; Mar: March; Apr: April.

\begin{tabular}{|c|c|c|c|c|c|c|c|c|c|c|c|c|c|}
\hline & Apr & May & June & July & 01Aug & 31Aug & Sept & Oct & Nov & Jan 12 & Fev12 & Mar12 & Apr12 \\
\hline Fatty acids & $* * *$ & $* * *$ & $* * *$ & $* * *$ & $* * *$ & $* * *$ & $* *$ & $* * *$ & $* * *$ & $\mathrm{~ns}$ & $\mathrm{Ns}$ & $* * *$ & \\
\hline Pigments & ns & $\mathrm{ns}$ & $\mathrm{ns}$ & ns & $*$ & $* *$ & $* * *$ & $\mathrm{~ns}$ & $\mathrm{~ns}$ & $* * *$ & $* * *$ & $* * *$ & \\
\hline Coll. sugars & $*$ & $* *$ & $* *$ & $*$ & $\mathrm{~ns}$ & $* * *$ & $\mathrm{~ns}$ & ns & $* *$ & $\mathrm{~ns}$ & $* *$ & $\mathrm{~ns}$ & \\
\hline Bound sugars & $*$ & ns & ns & $\mathrm{ns}$ & $* *$ & $* *$ & $*$ & $*$ & $* * *$ & $* *$ & Ns & ns & \\
\hline
\end{tabular}


6 Table 2: Results of ANOSIM pairwise post-hoc tests comparing experimental treatments using 4 sets of markers: fatty acids, pigments, colloidal

7 and bound sugars. All replicates (all samples pooled from all sampling dates) were used for each treatment. Test significance: ns: not significant;

$8 \quad *: \mathrm{p}<0.05 ; * *: \mathrm{p}<0.01 ; * *: \mathrm{p}<0.001$. Treatments were: Ctrl: no tubes; LD: low tube density; HD: high tube density. Tests for colloidal sugars

9 (Coll.sugars) were not performed as global test was not significant.

\begin{tabular}{l|ccc} 
& Ctrl LD & Ctrl HD & LD HD \\
\hline Fatty acids & $* * *$ & $* * *$ & $* * *$ \\
Pigments & $*$ & $* *$ & $\mathrm{~ns}$ \\
Coll. sugars & - & - & - \\
Bound sugars & $\mathrm{ns}$ & $*$ & $*$
\end{tabular}


Table S1: fatty acid percentages in sediment samples (mean over all samples from each treatment and sampling time; \pm standard error).

\begin{tabular}{|c|c|c|c|c|c|c|c|}
\hline $12: 0$ & 0.59 & \pm & 0.07 & $16: 2 \mathrm{w} 4$ & 0.51 & \pm & 0.05 \\
\hline $13: 0$ & 0.05 & \pm & 0.01 & $16: 2 \mathrm{w} 6$ & 0.19 & \pm & 0.02 \\
\hline $14: 0$ & 6.02 & \pm & 0.17 & $16: 3 w 4$ & 0.69 & \pm & 0.09 \\
\hline $15: 0$ & 3.15 & \pm & 0.13 & 16:4w1 & 0.03 & \pm & 0.01 \\
\hline $16: 0$ & 45.38 & \pm & 1.08 & $16: 4 w 3$ & 0.09 & \pm & 0.02 \\
\hline $17: 0$ & 0.87 & \pm & 0.03 & $18: 2 w 6$ & 0.33 & \pm & 0.04 \\
\hline 18:0 & 6.43 & \pm & 0.27 & $18: 2 \mathrm{w} 9$ & 0.08 & \pm & 0.02 \\
\hline 19:0 & 0.07 & \pm & 0.02 & $18: 3 w 3$ & 0.06 & \pm & 0.01 \\
\hline 20:0 & 0.24 & \pm & 0.02 & $18: 3 w 6$ & 0.79 & \pm & 0.13 \\
\hline $22: 0$ & 0.17 & \pm & 0.02 & $18: 4 w 3$ & 0.17 & \pm & 0.03 \\
\hline $24: 0$ & 0.13 & \pm & 0.02 & $20: 2 w 6$ & 0.84 & \pm & 0.13 \\
\hline$\sum$ SFA & 63.09 & \pm & 1.43 & 20:2w9 & 0.70 & \pm & 0.12 \\
\hline 14:0iso & 0.10 & \pm & 0.01 & $20: 3 w 6$ & 0.69 & \pm & 0.09 \\
\hline 15:0anteiso & 0.69 & \pm & 0.02 & $20: 4 w 3$ & 0.09 & \pm & 0.01 \\
\hline 15:0iso & 0.83 & \pm & 0.02 & 20:4w6 & 1.02 & \pm & 0.16 \\
\hline 16:0iso & 0.29 & \pm & 0.01 & $20: 5 w 3$ & 3.19 & \pm & 0.31 \\
\hline 17:0anteiso & 0.12 & \pm & 0.01 & $22: 2 w 9$ & 0.09 & \pm & 0.02 \\
\hline 17:0iso & 0.59 & \pm & 0.04 & $22: 3$ & 6.02 & \pm & 0.50 \\
\hline$\sum \mathbf{B F A}$ & 2.62 & \pm & 0.08 & $22: 4 w 6$ & 0.27 & \pm & 0.05 \\
\hline 14:1w3 & 0.01 & \pm & 0.00 & $22: 5 w 3$ & 0.25 & \pm & 0.04 \\
\hline 14:1w5 & 0.01 & \pm & 0.00 & 22:5w6 & 0.39 & \pm & 0.07 \\
\hline $15: 1$ & 0.04 & \pm & 0.01 & 22:6w3 & 0.11 & \pm & 0.02 \\
\hline 16:1w5 & 0.35 & \pm & 0.04 & $\sum$ PUFA & 16.63 & \pm & 0.45 \\
\hline $16: 1 w 7$ & 13.77 & \pm & 1.21 & & & & \\
\hline 16:1w9 & 0.13 & \pm & 0.02 & & & & \\
\hline 17:1w7 & 0.02 & \pm & 0.00 & & & & \\
\hline 17:1w9 & 0.16 & \pm & 0.02 & & & & \\
\hline 18:1w11 & 0.14 & \pm & 0.03 & & & & \\
\hline 18:1w5 & 0.08 & \pm & 0.03 & & & & \\
\hline 18:1w7 & 0.91 & \pm & 0.09 & & & & \\
\hline 18:1w9 & 1.31 & \pm & 0.11 & & & & \\
\hline 19:1w9 & 0.04 & \pm & 0.01 & & & & \\
\hline 20:1w11 & 0.03 & \pm & 0.01 & & & & \\
\hline 20:1w7 & 0.02 & \pm & 0.00 & & & & \\
\hline 20:1w9 & 0.02 & \pm & 0.01 & & & & \\
\hline $22: 1 w 11$ & 0.34 & \pm & 0.06 & & & & \\
\hline 22:1w9 & 0.30 & \pm & 0.05 & & & & \\
\hline$\sum$ MUFA & 17.67 & \pm & 1.38 & & & & \\
\hline
\end{tabular}


Table S2: pigment percentages in sediment samples (mean over all samples from each treatment and sampling time; \pm standard error).

\begin{tabular}{l|cc} 
Chlorophyll $a$ & $47.64 \pm 0.37$ \\
Chlorophyll $b$ & 0.14 & \pm 0.04 \\
Chlorophyll $c$ & 7.35 & \pm 0.17 \\
Chlorophyll $a$ epimer & $2.38 \pm 0.08$ \\
Chlorophyllide $a$ & $4.88 \pm 0.40$ \\
Alloxanthin & $8.47 \pm 0.25$ \\
Diadinoxanthin & $4.19 \pm 0.16$ \\
Fucoxanthin & $23.51 \pm 0.39$ \\
Pheophytina & $0.96 \pm 0.12$ \\
B-Caroten & $0.43 \pm 0.03$
\end{tabular}


Table S3: carbohydrate percentages in sediment samples (for each fraction, mean over all samples from each treatment and sampling time; \pm standard error).

\begin{tabular}{l|cc|cc} 
& \multicolumn{2}{|c|}{ Bound } & \multicolumn{2}{c}{ Colloidal } \\
\hline Fucose & 2.62 & \pm 0.17 & 1.67 & \pm 0.13 \\
Galactose & 5.30 & \pm 0.20 & 5.39 & \pm 0.22 \\
Galacturonic acid & 0.85 & \pm 0.19 & 0.79 & \pm 0.18 \\
Glucose & 71.53 & \pm 0.87 & 77.47 & \pm 0.82 \\
Glucuronic acid & 0.13 & \pm 0.02 & 0.11 & \pm 0.03 \\
Mannose & 8.29 & \pm 0.32 & 6.89 & \pm 0.30 \\
Myo-inositol & 1.15 & \pm 0.08 & 0.46 & \pm 0.07 \\
Rhamnose & 0.76 & \pm 0.07 & 0.94 & \pm 0.06 \\
Scyllo-inositol & 3.55 & \pm 0.36 & 2.80 & \pm 0.23 \\
Xylose & 5.81 & \pm 0.31 & 3.49 & \pm 0.26
\end{tabular}




\section{Figures captions}

2 Fig. 1: Non-metric Multidimensional Scaling (nMDS) plot of Bray Curtis similarities of the fatty acid (FA) compositions of sediment over the course of the experiment. For each date, all replicates from each treatment are displayed. Data were transformed with Hellinger transformation prior to analysis. The low value of stress indicates that the grouping representation is meaningful: distances between symbols correlate well with dissimilarities between the FA compositions of sediment. Ctrl treatment: circles; LD treatment: squares; HD treatments: triangles. Apr: April; Jun: June; Jul: July; Aug: August; Sept: September; Oct: October; Nov: November; Jan: January; Feb: February; Mar: March.

Fig. 2: Non-metric Multidimensional Scaling (nMDS) plot of Bray Curtis similarities of the pigment compositions of sediment over the course of the experiment. For each date, all replicates from each treatment are displayed. Data were transformed with Hellinger transformation prior to analysis. The acceptable value of stress indicates that the grouping representation is acceptable: distances between symbols correlate with dissimilarities between the pigment compositions of sediment. Ctrl treatment: circles; LD treatment: squares; HD treatments: triangles. Apr: April; Jun: June; Jul: July; Aug: August; Sept: September; Oct: October; Nov: November; Jan: January; Feb: February; Mar: March.

Fig. 3: Non-metric Multidimensional Scaling (nMDS) plot of Bray Curtis similarities of the monosaccharide composition in colloidal EPS over the course of the experiment. For each date, all replicates from each treatment are displayed. Data were transformed with Hellinger transformation prior to analysis. The acceptable value of stress indicates that the grouping representation is acceptable: distances between symbols correlate with dissimilarities between the pigment compositions of sediment. Ctrl treatment: circles; LD treatment: squares; HD treatments: triangles. Apr: April; Jun: June; Jul: July; Aug: August; Sept: September; Oct: October; Nov: November; Jan: January; Feb: February; Mar: March. 
Fig. 4: Non-metric Multidimensional Scaling (nMDS) plot of Bray Curtis similarities of the monosaccharide composition in bound EPS over the course of the experiment. For each date, all replicates from each treatment are displayed. Data were transformed with Hellinger transformation prior to analysis. The acceptable value of stress indicates that the grouping representation is acceptable: distances between symbols correlate with dissimilarities between the pigment compositions of sediment. Ctrl treatment: circles; LD treatment: squares; HD treatments: triangles. Apr: April; Jun: June; Jul: July; Aug: August; Sept: September; Oct: October; Nov: November; Jan: January; Feb: February; Mar: March.

Fig. 5: Results of MFA analysis on sediment samples over the course of the experiment: a. correlation circle between variables used for the analysis; b. confidence ellipses grouping sediment samples from each month. Datasets used for the experiment were fatty acids, pigments, and monosaccharide composition of colloidal and bound EPS. Apr: April; Jun: June; Jul: July; Aug: August; Sept: September; Oct: October; Nov: November; Jan: January; Feb: February; Mar: March. Chla, Chlb, Chlc: chlorophylls a, b and c, respectively. C:

Colloidal EPS. B: Bound EPS. AGlu: Glucuronic acid. AGal: galacturonic acid. Fuc: Fucose. Gal: Galactose. Glu: Glucose. Man: Mannose. Myo: Myo-inositol. Rha: Rhamnose. Scyl: Scyllo-inositol. Xyl: Xylose. 


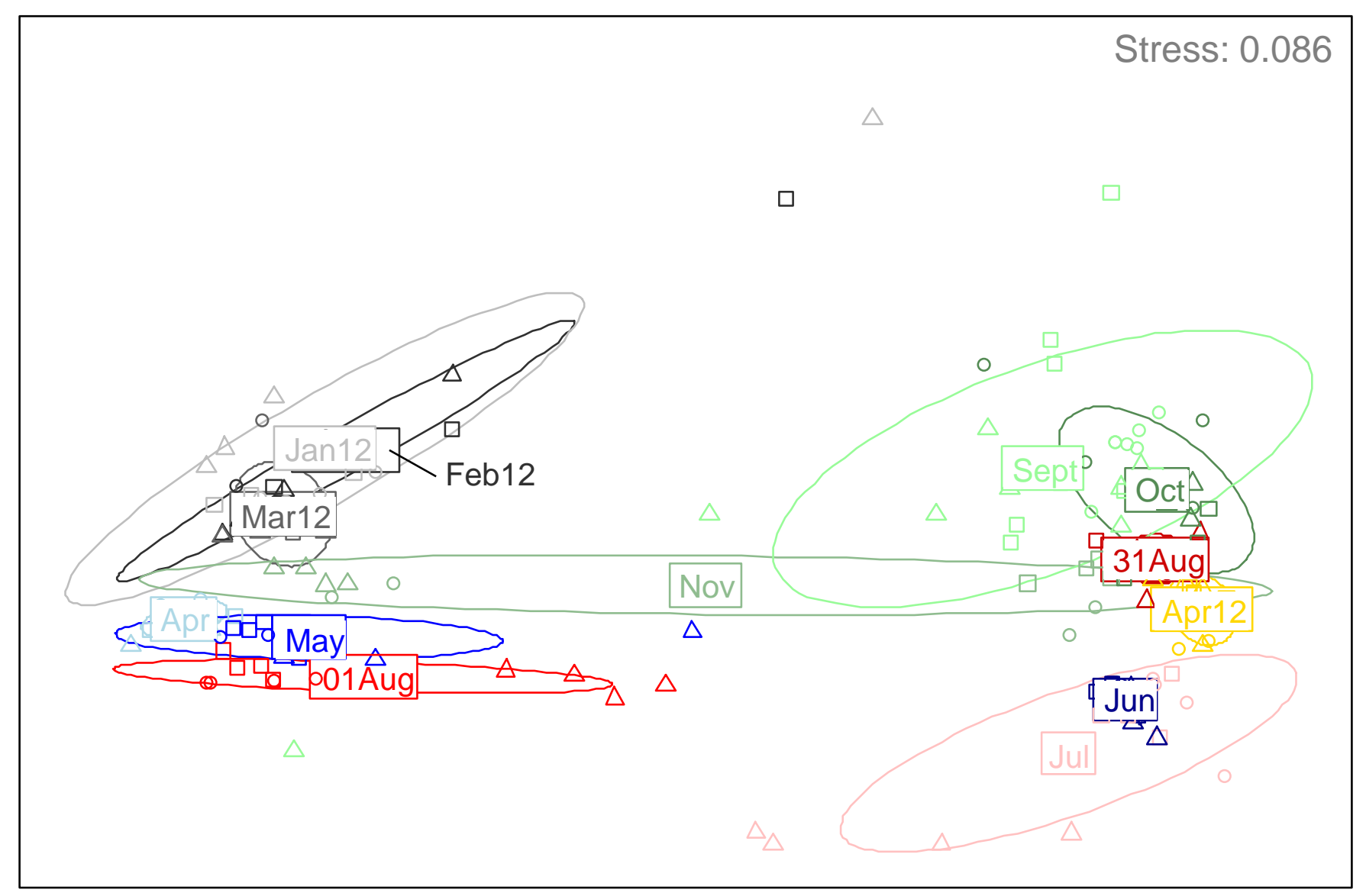


Fig. 2

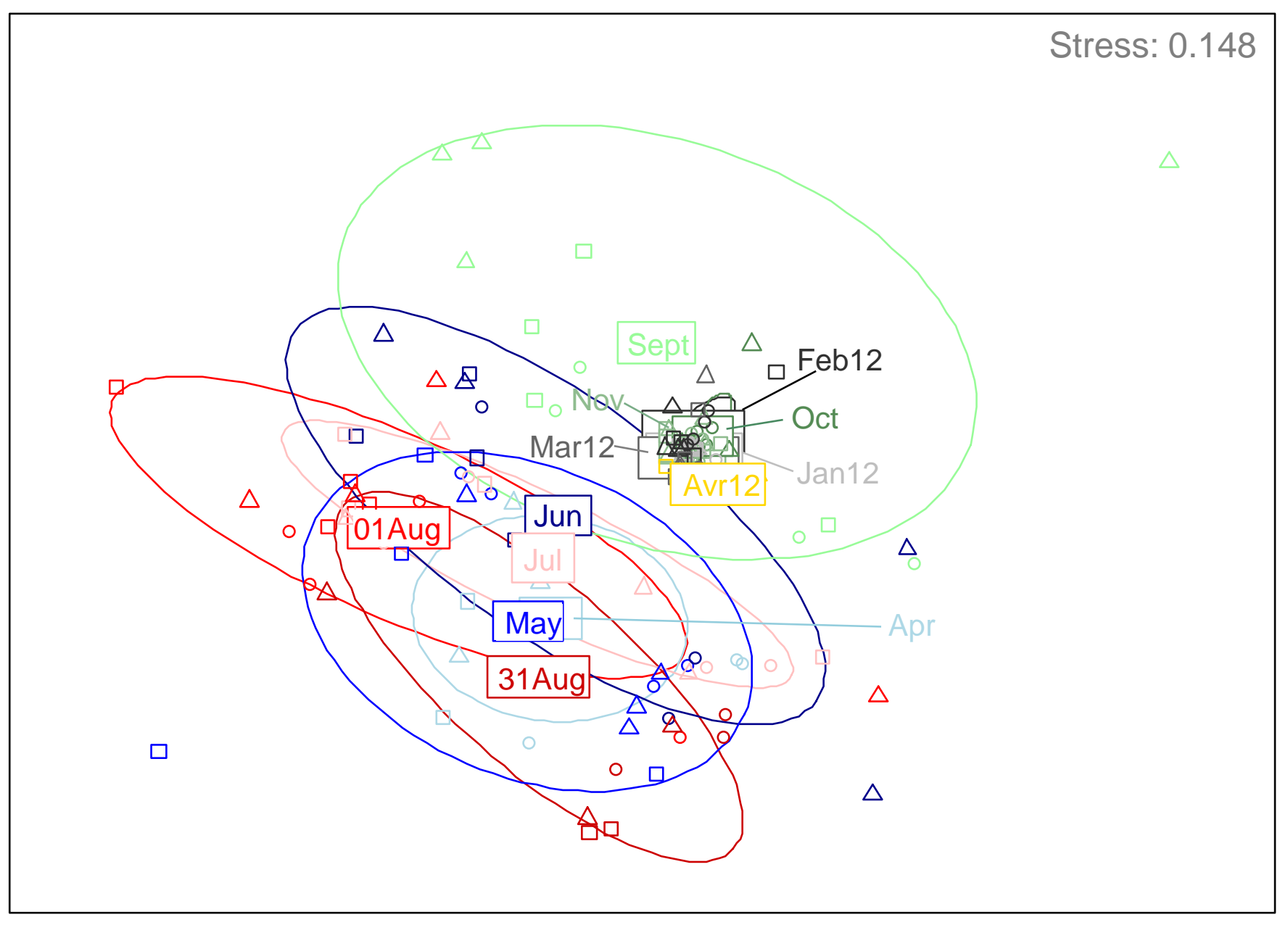


Fig. 3

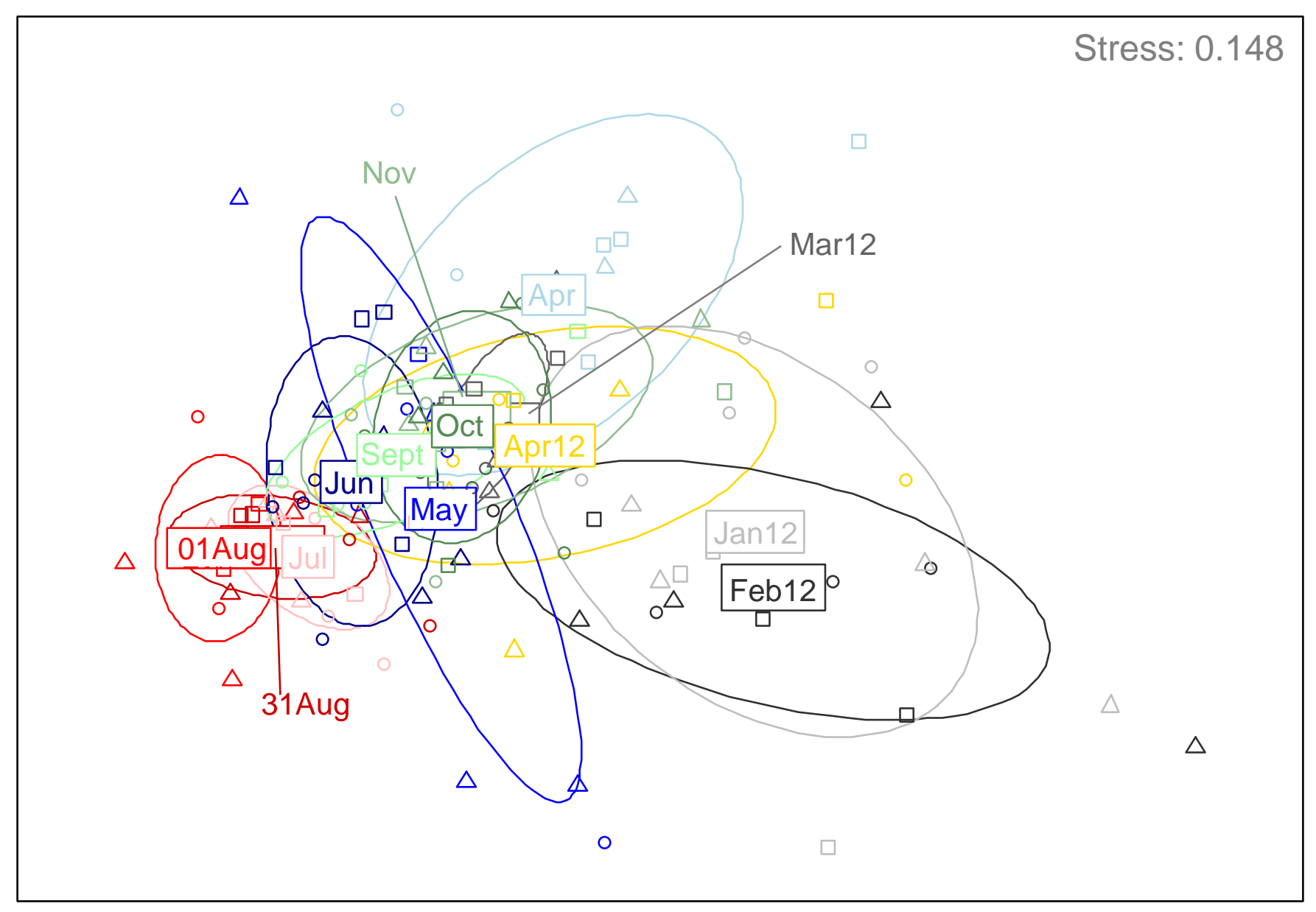


Fig. 4

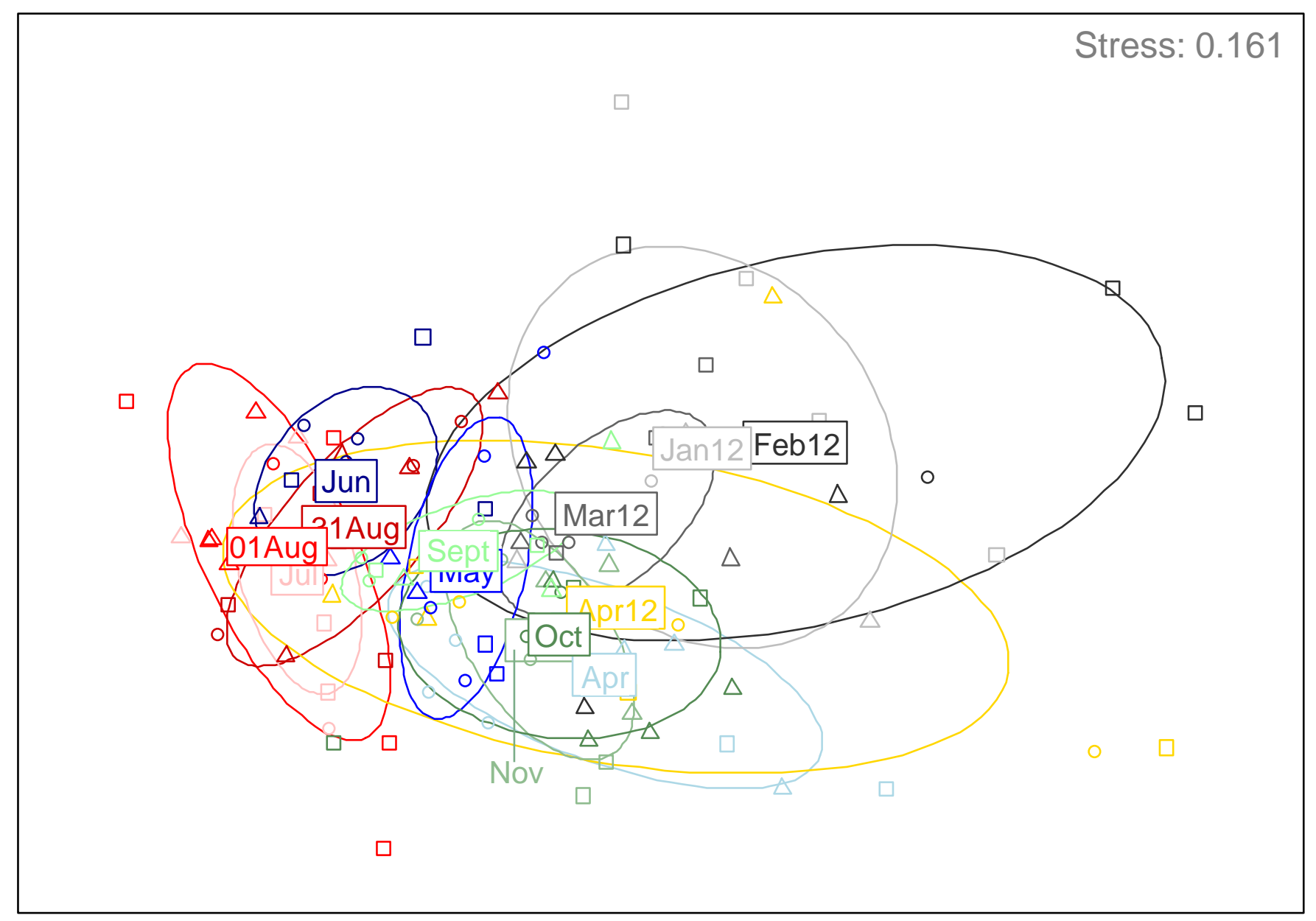


Fig. 5

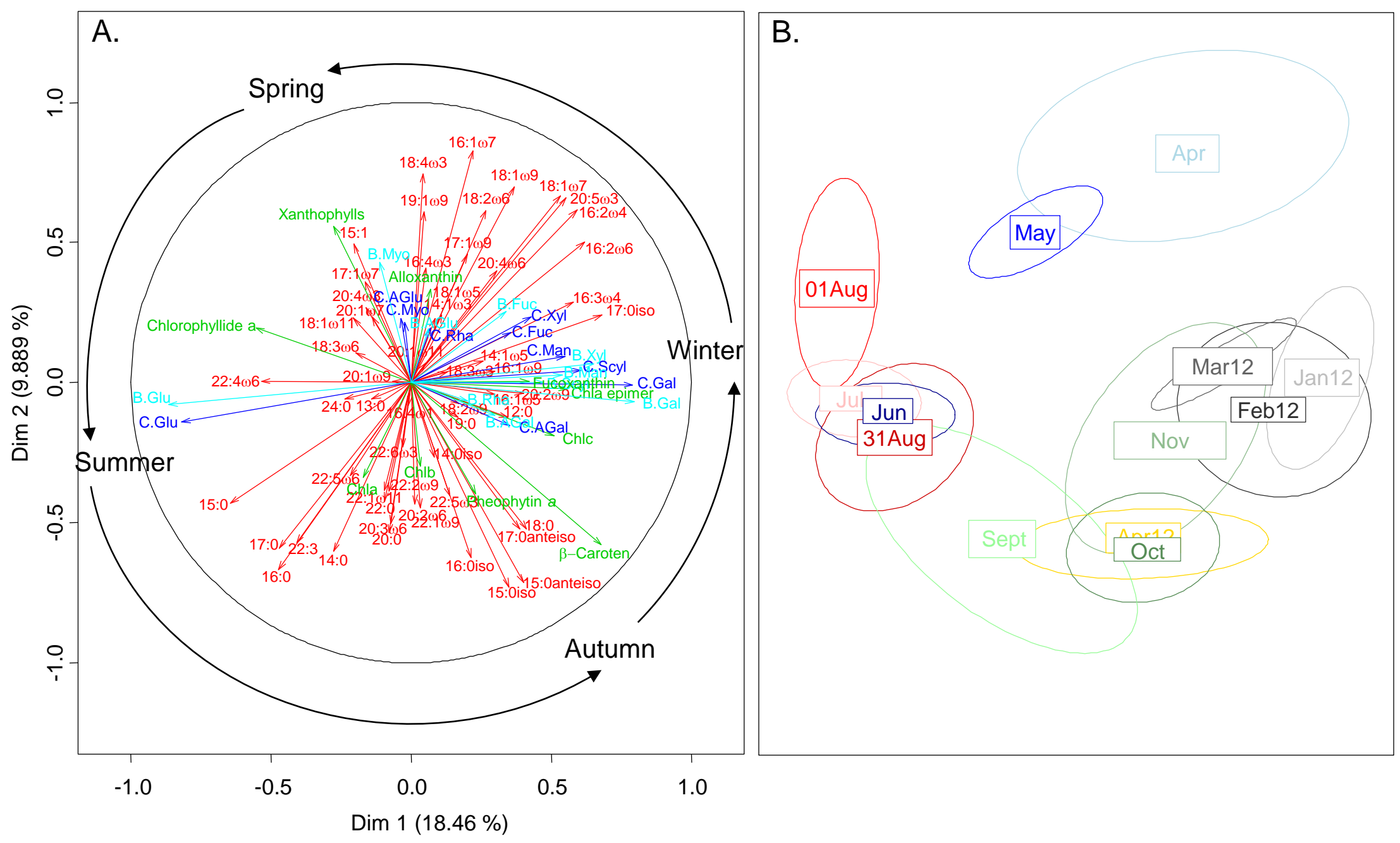


Supplementary figures: captions

Fig. S1: evolution of total fatty acid (FA) concentrations in sediment over the course of the experiment. The $\mathrm{x}$ axis displays the number of days from the beginning of the experiment (March 21st, 2011). Treatments were : no tubes (Ctrl, grey circles); low tube density (LD, empty square) and high tube density (HD, black triangles).

Fig. S2: evolution of total pigment concentrations in sediment over the course of the experiment. The $\mathrm{x}$ axis displays the number of day from the beginning of the experiment (March 21st, 2011). Treatments were : no tubes (Ctrl, grey circles); low tube density (LD, empty square) and high tube density (HD, black triangles).

Fig. S3: evolution of total EPS concentrations: a. carbohydrates and b. proteins in sediment over the course of the experiment. The $\mathrm{x}$ axis displays the number of day from the beginning of the experiment (March 21st, 2011). Treatments were : no tubes (Ctrl, grey circles); low tube density (LD, empty square) and high tube density (HD, black triangles). 


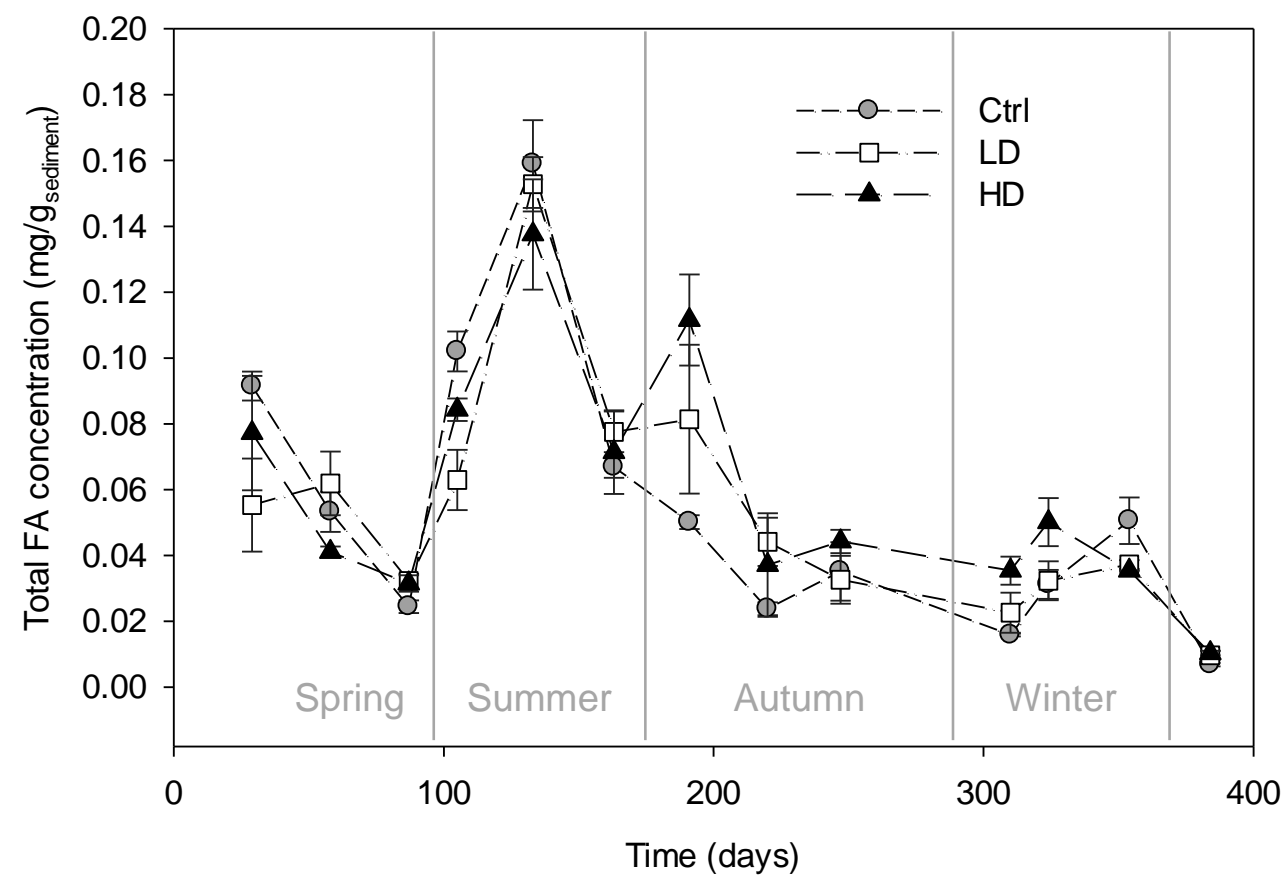




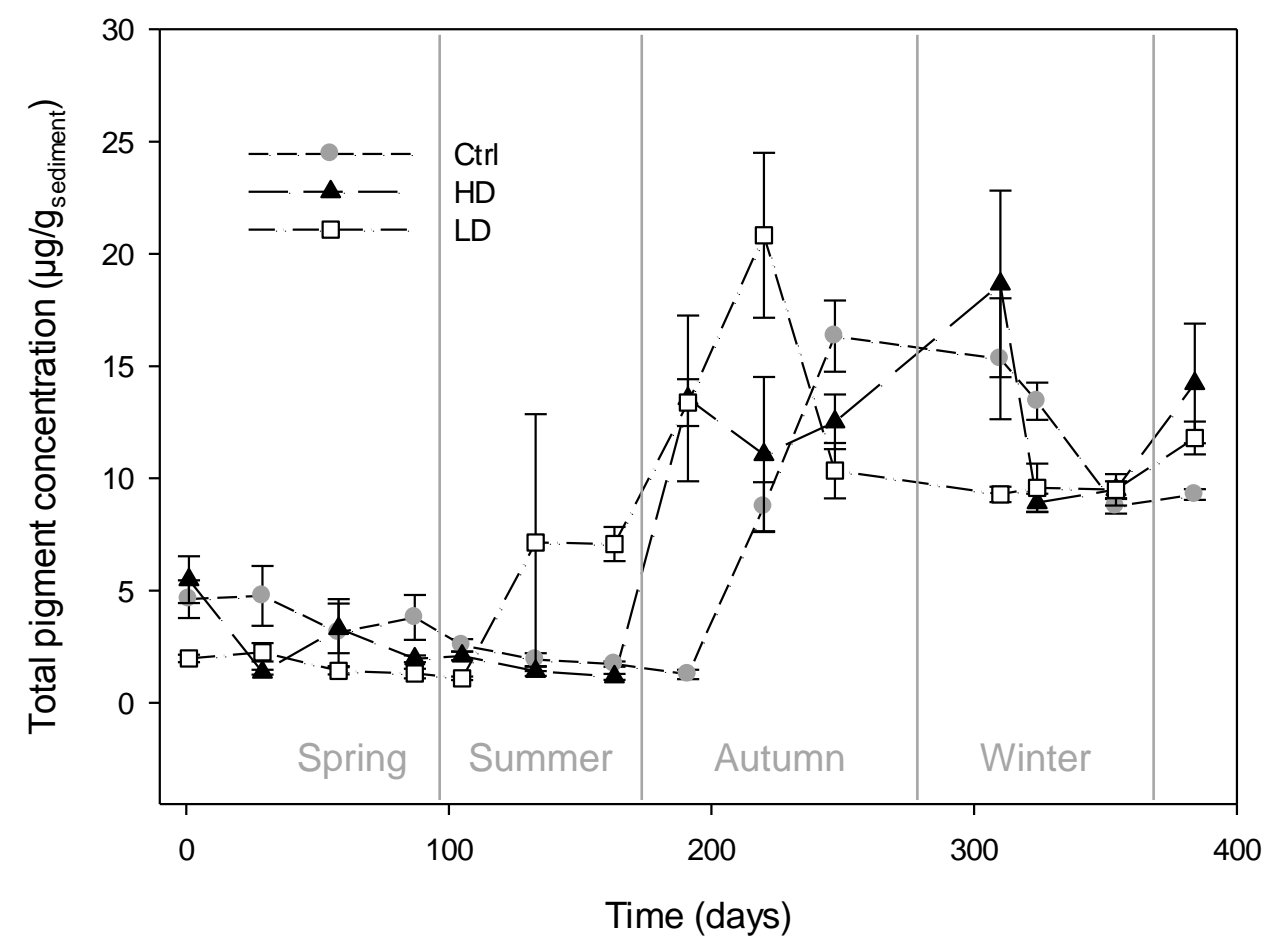


Fig. S3
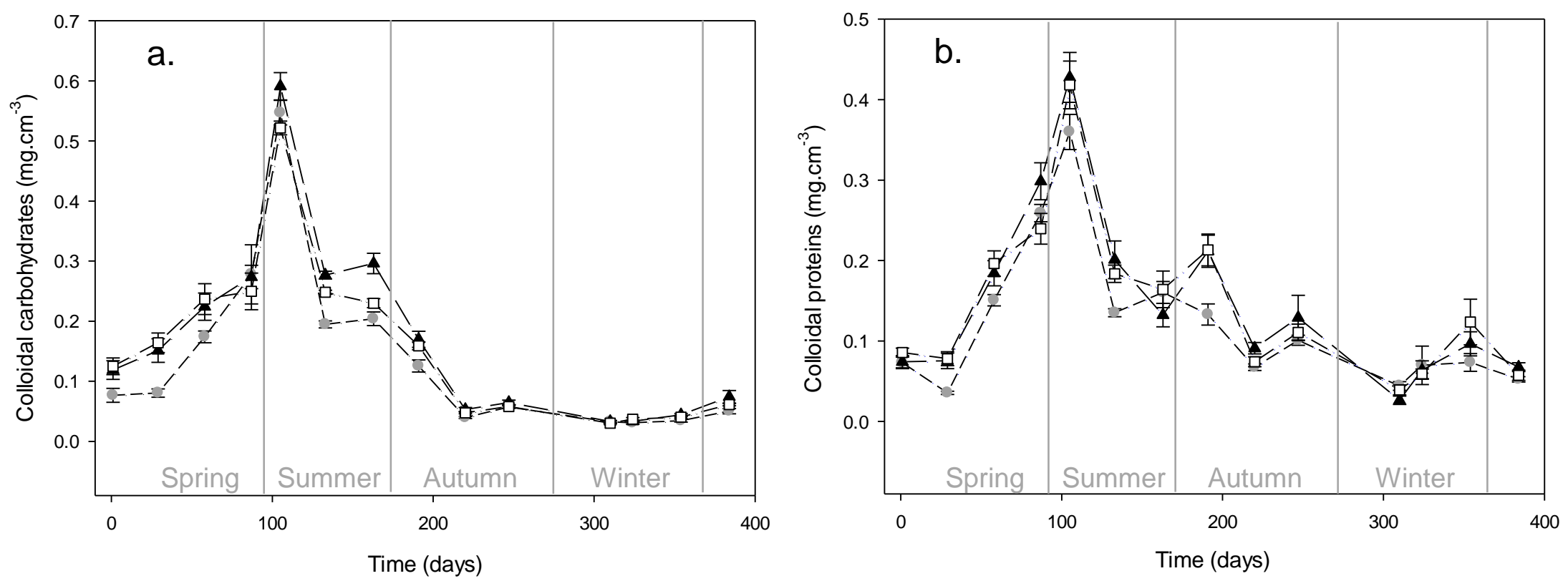